\title{
An Innovative Media Platform-Supported Blended Methodology in English for Dental Purposes Program
}

\author{
https://doi.org/10.3991/ijet.v12i03.6441 \\ Jafar Asgari Arani \\ Kashan University of Medical Sciences, Islamic Republic of Iran \\ Askari@kaums.ac.ir
}

\begin{abstract}
Due to the existing extensive curricula of English for Dental Purposes (EDP) courses and absence of enough weekly hours to cover them in Iran, there is a limited insufficient exposure to English to improve students' English communication skills to the levels necessary for their future career. Therefore, there have been needs to appraise the present teaching approaches and reform the configuration and context of EDP classes to yield highest profit for their students. The study was designed to address issues central to the perception and expectations of students in regard the use and the impact of the social medium, WhatsApp. As part of this impression, a spectrum of procedures has been depicted to employ this cross-platform messaging application.

This research was conducted among $702^{\text {nd }}$ year dentistry students at Kashan University of Medical Sciences, in a course called English for Dental Purposes (EDP). The descriptive research project employing a qualitative and quasiexperimental study was chosen to collect data using a valid and reliable pretestposttest design. Two groups 35 subjects were randomly selected via simple random sampling. The control group was taught by conventional method, while the experimental group was taught through the proposed whatsApp assisted language learning approach in a blended way. A paired t-test was utilized to compare the results of each group and an independent sample t-test was utilized to compare the results in control and experimental group. The $f$-ratio value is 7.88138; the $t$-value is 2.80738 . The $p$-value is .006512 and the result is significant at $p<.01$.

Therefore, there are good reasons to think WhatsApp-based method of teaching EDP as a more effective approach than the face to face method. The Likert scale questionnaire descriptively analyzed via SPSS 16.00 version revealed experimental group had generally positive attitudes towards Apps-based teaching of academic materials.

This media helps students get to be more capacitated in EDP, advances the class learning of English for Dental Purposes, enhances students' knowledge more satisfactorily, motivates them to gain a positive impact and willingness in their class activities and had resulted in more continuity in study and selfconfidence. So, it deserves considering the incorporation of the new application i.e. WhatsApp effectively in the curriculum of EDP pedagogies as an educational means.
\end{abstract}

Keywords-WhatsApp; English for Dental Purposes; Blended Language Learning 


\section{Introduction}

Whatsapp has become so pervasive with mobile exploiters that it has promoted communicating in many ways. Utilizing a mobile phone and an internet connection, people can readily communicate all contacts in their WhatsApp users list.

The basic aim of WhatsApp is to facilitate communication, and at its most underlying level, education is nothing but communication. Through Whatsapp channel teachers can attain faster and easier communication with their students. It can elevate the level of communication between students and create another field for learning. This medium is may be viewed as an aid of communication and a tool of circulating educational resources and information to students.

The truth that it is already a favorite with the general public due to the convenience of using it could be the greatest purpose to recollect it for applying in education. In general, the function of appearing social media can also present new chances to promote the teaching and learning. Zepke and Leach [47] deduce that motivation and student temperament will affect their ability to involve in interactive learning.

In addition, nowadays students, often denoted as "digital natives" [36], have spent most of their time on computers, game consoles, digital music players, video cameras, cell phones, as well as the Web itself. Getting used to permanent involvement in their daily tasks, students require a high level of social and productive assignment in learning. Therefore, according to Jovanovic et al. [22] traditional teaching approaches benefiting passive content utilization, are no more appropriate and have to be swapped, or at least supplemented, with highly interactive learning processes.

\section{$2 \quad$ Literature Review}

An approach based on modern mobile instruments would result in improvement of students' micro-skills for and motivation in writing, mainly through peer coaching, which is highly adaptable either by the teachers (i.e., differentiated instruction through customization of the writing process) or the students themselves (i.e., autonomous learning - choice of how to make use of the group generated resources for their own writing) to suit the learning proficiency levels of individual student groups, and would turn the students' individual differences in the proficiency levels of various micro-skills from a perceived instructional challenge to an advantage in motivating effective peer coaching in English for specific purposes [32]. Although there is a vast body of surveys on conventional text messaging practices, little is realized about how and why people have assumed and utilized messaging application [10].Majority of students in a pilot project considered the educational program offered to be efficient, useful and beneficial. In this project, the data gathered revealed supplementary SMSs in a blended approach could be integrated into EMP (English for Medical Purposes) course to enable students to develop better English sentence paraphrasing skills. In this research it has been found that apps can be used for language learning, especially English; students receiving short complementary lessons on their mobile phones via SMS are more enthusiastic and learned more than their counterparts in conventional group [3]. The fact that WhatsApp is free (for most people) makes it specifically ap- 
pealing for general presentability. Gutierrez et al. [15] present a project with university students in Spain to inquire into the benefits and drawbacks of using instant short messaging systems such as WhatsApp to improve learners' reading skills in English as a foreign language. Riyanto [38] also examines the use of this social medium for the four language skills: reading, writing, speaking and listening, the process consisting common questions on versatile topics, delivering them to all the members in the group through a program, employing them in meaningful forum.

Some of the research projects implying the implementation of different systems of messaging between educators and students are : capacity for learning improvement [40]; capability for learners to be active in their studies [11]; ordinary conversation between students [11] \& [40]; profound communication between students and lecturers related to course content [11]; sense of attachment and community [12]\&[41]; breaking teacher-student social limits [12]; and students inclination to take home works more seriously when they are public to affect their peers [41]. Although, some teachers felt distressing with the non-academic and social categories [12], others believed that messaging has a negative effect on academic writing as students begin to pass over vowels and punctuation [41].

Also, smart phones in the market have prompted increasing use of WhatsApp as a communication program for student groups, and for groups of teachers and their students as well. Teachers may build groups for their students comprising a type of "simple social network" for the class [13] \& [26]. Church and de Oliveira [10]are of the opinion that people adopted WhatsApp as their main not alternative means of communication due to the low cost of the application coupled with the ability to send an unlimited number of messages, immediacy, the demand to feel a section of the procedure since their familiarity have already accepted the application, the ability to follow a continuous dialogue with many friends synchronously, the uniting together of a community of friends or family, and a sense of confidentiality relative to other social networks. Some drawbacks like massive irrelevant and considering application as informal oriented people formalize text messages whenever they feel they should deliver convey an important or impressing message.

Since WhatsApp is relatively a new phenomenon, little research exists regarding its impact on interpersonal communication in general, and between teachers and their students in particular [10]. A survey on the use of WhatsApp in a South African university class stated positive feedback from students who believed that it was an easier way to communicate with their teachers and the rest of the class. They thought it contributed to beneficial discussion on relevant issues in an informal environment where students could study with friendship and eagerness, and that it was also pleasant [5]. Such cooperation was thought to make a connection between knowledge and physical distance. In general, WhatsApp has become a common platform promoting proximity, strengthening agreement, and inspiring provocation to function actively in academic practices [5]; [9].

A research done among Spanish students, explored the use of WhatsApp in English language studies. Some students declared their provocation rose and had greater eagerness for studying foreign language [15]. However, another study in Kuwait reported its drawbacks in developing students' writing skill [39]. 


\section{Whatsapp in ESP, EMP, and EDP}

English for Special Purposes (ESP) is a teaching approach to English language in which "all decisions as to content and method are based on the learners' reasons for learning" [19]. ESP courses are, in fact, complied with the specialized needs of the students. WhatsApp has been acquiring great basis in view of its release time. However, due to its teaching at university, the potential of this media is yet to be investigated in more extensive dimensions.

Various studies have been done to gain results on the application of this app in education and English teaching and learning contexts. A research by Yeboah and Ewur [46]in education indicates that WhatsApp is a necessary instrument for students in higher education institutions in Ghana having both its own positive and negative effects. Another research by Bouhnik and Deshen [6] specifies both educational and academic benefits of WhatsApp and its technical, educational and academic challenges. In the field of English Language Teaching (ELT), a few investigators have reported potential advantages of 'mobile learning' and blended learning. Some of the inquiries have reported the use of smart phones promotes students' listening and speaking skills [25], while other researches confirm that the capacity for reading comprehension can be upgraded via application of text messages [33]. Also another survey aimed at collecting and analyzing data on a prospective project design in teaching "English for Medical Purposes" (EMP) to the students and graduates of medicine in the areas such as choices and opinions about different m-learning Apps options for Medical English: SMS \&SMS + IVR (Interactive Voice Response) for listening and Educational Games concludes that technology tools have the potential to be given strong consideration in teaching and learning writing within their learning management system [2].

To benefit from advances in educational widgets, language learning and teaching appears to be the most qualified to apply them to handle learner's didactic demands. Some language educator researchers have studied the persuasive effect of mobile phones potentials specifically messaging as educational stages on university students [29], [8],[30], [42]. In these surveys messages have been viewed as medium by which teaching linguistic segments is facilitated. According to Thonton \& Houser [42], when exposed to this educational tool at a regular design, students would be persuaded to improve in the process. These investigations, however, have not thoroughly analyzed its effectiveness on all various skills while teaching and/learning language subdivisions sub skills through WhatsApp. In addition, teaching some language process items like punctuation, word formation, sentence comprehension and interpretation, phrase and clause levels, among all, have not been paid so much attention in mobile and blended teaching procedures. Notwithstanding, some items obligate educators to consider them uniquely in language teaching programs because they are gone through both oral and written communication so that they don't have to be have to be changed to an optional function or significance[23],[24], [18]. However, it is assumed that the use of WhatsApp has not yet been surveyed completely in EDP in tertiary education settings. 


\section{$4 \quad$ Problem Statement}

Due to the existing extensive curricula of English for Dental Purposes (EDP) courses and absence of enough weekly hours to cover them in Iran, there is a limited exposure to English which is insufficient to improve students' English communication skills to the levels necessary for their future career. So, there have been needs to appraise the present teaching approaches and reform the configuration and context of EDP classes to yield highest profit for their students [20]; [21]. As part of this impression, a spectrum of procedures have been depicted and applied.

With advancement of digital media, it is believed that some effective form of educational innovative tools will help handle this trouble.

Hemmi, Bayne and Land [17] maintain that since students already cooperate, search for information, communicate, and spend their free time using web technologies there is no reason not to apply the media in the classroom to support learning. However, how these tools are employed and integrated into the learning process is vital. In this study, the researcher was trying to explore the application and the effect of WhatsApp as an educational media on teaching and learning English for Dental Purposes (EDP) course.

\section{$5 \quad$ Research Question}

The study sought to address queries, which were central to the perception and prospect of students in regard the use and the impact of social media:

How is the effect of the WhatsApp-based method of teaching EDP on the Dentistry achievement?

Do dentistry students find any noteworthy points using this App motivating them in learning EDP?

Do our students believe that the application of these media as educational tool can enhance and supplement class activities in English for Dental Purposes course?

\section{$6 \quad$ Participants}

This research was conducted among 70 dentistry students at Kashan university of Medical Sciences, in a course called English for Dental Purposes (EDP) during the first semester of the academic year 2015-2016. The descriptive research project employing a qualitative and quasi-experimental study was chosen to collect data using a valid and reliable pretest-posttest design to analyze the adequacy and effect of applying mobile WhatsApp for the enhancement of teaching this course to the students.

\section{$7 \quad$ Design \& Method}

This quasi-experimental project was specified within some novel concepts addressing pervasive learning and the idea of utilizing cell phone as a supplementary medium 
in performing alone on assignments as theorized by investigators like $\mathrm{Lu}$ [31], Kennedy \& Levy [29], and Cavus \& Ibrahim [8]. This work was contrived to comply with plan rules Gu et al. [14] designed implying subject matters, performance and applicability. The educational materials were in line with students' professional practical needs in the curriculum. The performance was made through actions like English structural points. The applicability of the WhatsApp activities was to concentrate on the needs to attract students' attention and to keep subject matter fresh in their mind [14].

All the students were admitted and entered to the university through the University Entrance Exam administered by the Ministry of Medical Education, so that they may be considered to be at the same knowledge level. Two groups of 35 subjects were randomly selected via simple random sampling. The control group was taught by conventional method, while the experimental group was taught through the proposed what's App assisted language learning approach. The latter received complementary WhatsApp contents through the panel in a scheduled pattern of delivery three times a week to strengthen their learning EDP. The delivered contents involved a set of EDP materials that according to previous appraisals the students were not exposed to sufficiently. They outlined and expressed a) word morphology and terminology, b) structural points in paraphrasing and sentence writing, and c) oral presentation points like listening tactics, note making, and note taking.

\section{Data Collection and Analysis}

Quantitative and qualitative methods were employed both to maximize the domain and the depth of the perceptions achieved [37], and to capture "richer interview data supplementing the more extensive questionnaire results" [44] \&[28].

A multiple-choice posttest was designed in the light of EDP curriculum devised by the Ministry of Medical Education involving the contents mentioned in the outline.

Then, it was administered to the students of both the experimental and control groups to make sure that they were at the same level of performance before starting the experiment; and hence the progress the experimental group students achieved could be ascribed to the teaching program they received through using WhatsApp approach. The post-test was used to study the efficacy of the using WhatsApp as a blended technique in teaching to develop students' comprehension skill.

A paired t-test was utilized to compare the results of each group and an independent sample t-test was utilized to compare the results in control and experimental group. The $f$-ratio value is 7.88138 ; the $t$-value is 2.80738 . The $p$-value is .006512 and the result is significant at $p<.01$. It was found that control and experimental groups improved their EDP. However, the results of independent t-test indicated a significant statistical difference between them, therefore, there are good reasons to think WhatsApp-based method of teaching EDP as a more effective approach than the face to face method. The findings of these analyses are presented in tables 1 and 2 . 
Table 1. Data Summary

\begin{tabular}{|c|c|c|c|}
\hline & Exp. & Conv. & Total \\
\hline $\boldsymbol{N}$ & 35 & 35 & 70 \\
\hline$\sum \boldsymbol{X}$ & 478 & 414 & 892 \\
\hline Mean & 13.65714 & 11.8286 & 12.7429 \\
\hline$\sum \boldsymbol{X}^{2}$ & 6854 & 50757 & 11930 \\
\hline Std. Dev. & 3.09594 & 2.2943 & 2.8574 \\
\hline
\end{tabular}

Table 2. Result Details

\begin{tabular}{|c|c|c|c|c|}
\hline Source & SS & df & MS & \\
\hline Between-Groups & 58.5143 & 1 & 58.5143 & $\mathrm{~F}=7.88138$ \\
\hline Within-Groups & 504.8571 & 68 & 7.4244 & \\
\hline Total & 563.3714 & 69 & & \\
\hline
\end{tabular}

To perceive experimental group development thoroughly [7] \& [27], the participants were interviewed using a semi -structured questionnaire entailing 16 questions adopted from the surveys of Attewell et al. [4]and, Gutiérrez et al. [15] .

Data from the students survey responses, and interviews, of their use of the medium were analyzed to find out and describe the participants attitudes toward the whatsApp application as a supplementary means of EDP course .

According to the data obtained, this media helps $75 \%$ of students increase their EDP interest outside the class and persuaded most of them (81\%) to study it at their free time and anywhere (62\%) since they have supplementary EDP materials in their phone repository to review $(62 \%)$ so that the project enhanced their special English class learning (59\%). The project advances students' writing homework (49\%) and caused 54\% of the dentistry students' answer its exercises more quickly. Therefore, $51 \%$ of them developed their special writing activity. This approach also lessens English class stress $(77 \%)$ while strengthening students' self-confidence (81\%), thus enhancing students' knowledge more satisfactorily, and motivating them to gain a positive impact and willingness in their class activities.

In addition, since some class matters are delivered through the supplementary medium, WhatsApp, some of the class time may devoted to more difficult points. The feeble students may refer to the messages to review and scrutinize all the class materials .Therefore, $41 \%$ of the students strongly agree or agree $(18 \%)$ with this time saving property of the project.

However, the drawbacks commented by the students were poorly formulation of some materials $(54 \%)$, necessity of longer texts $(69 \%)$ to include examples $(71 \%)$, and incomplete messages $(21 \%)$ due to technical problems. Some students supposed that each message should build upon the next, progressively increasing the language level $(71 \%)$. 


\section{Conclusion}

According to study results, the students are amenable to exploit WhatsApp in EDP course, and they are of the opinion that such use will enhance their experiences in learning, academically and psychologically. Students' perceptions of WhatsAppbased approach use were particularly positive and surprisingly promising. They believed that the approach enhanced their learning of English for Dental Purposes.

In the field of implementing WhatsApp-based actualizing system to reinforce EDP class, the noteworthy point was the necessity to settle a procedure proposing many of the text messages and exercises deliveries in a way to disconnect teacher's dependence on complete class presentation of the educational materials according to a preset syllabus.

According to the findings of the study, it is suggested in mobile teaching and learning to use WhatsApp mobile application only to pursue learning activities in a blended course integrating both face to face learning and mobile learning. Therefore, WhatsApp is a good media for mobile learning when it is used in a blended course . The results of the present research show that WhatsApp mobile language learning activities carry benefits for university students' achievement and attitudes towards blended learning and teaching.

This medium helps students get to be more equipped in EDP, and advances the utilization of English for communicating materials be told and it helps in expanding the language expertise of the learners. Using this approach, some students can do extra practice outside the classroom and review class materials available in their cell phones storage, so that the teacher is not supposed to back off whatever remains of the class for feeble students in class in an extra time. The medium also permits the instructor to keep up student enthusiasm by giving students progressed materials. Generally speaking, the study uncovered that the WhatsApp-based teaching system could be viewed as an effective medium for supplementary teaching and learning English issues as well. A language instructor may find that $\mathrm{m}$ learning gives simply the right sort of student-teacher interaction that will motivate the class learning and persuade the students doing homework at their free time. Therefore, language instructors ought not to neglect the indubitable estimation of conventional classroom adapting, yet the genuine capability of learning with multifaceted innovations ought to be generally gratified [16]. Traditional methods of special English teaching are not so appropriate for university students which is consistent with the study conducted by Nguyễn et al. [35]indicating that since technical facilities and media for teaching ESP at educational institutions are mainly rarely useful, teachers should apply information technology media for increasing lectures' attraction, motivation as well as saving time and effort.

The alternatives could be the modern digital media like WhatsApp. WhatsAppbased approach is a continuous process of learning, teaching and assessment that never ends and gives a real chance to practice the language beyond the walls of classrooms. The findings of the present survey are also in accordance with the results of another study [45] by expressing that instructions applying online media are more effective when combined with attending face-to-face lectures. 
It has been proclaimed that the students are highly motivated psychologically to use the WhatsApp. In this regard, this research findings show the consistency with the previous studies conducted about the use of media like Facebook and Mobile Phone technology among the student [1] \& [43].

\section{Implication}

The framework for a WhatsApp-based approach in a special English course in university is available with many teachers and a vast majority of the students; however, the administrative educational prospect to plan and develop it is not sufficient for both of them. Further qualitative research will impel the implementation of WhatsAppbased approaches to include into educational and pedagogical English curriculum.

It is implied that since messaging texts delivered are supplementary educational tools offering multiple learning and instructional opportunities, they could include examples, quizzes with immediate feedback, class monitoring and supervising widgets, classroom response system as a tool for planning language skills development, integrated with more 'game' elements [34]in other studies. Moreover, as this research was a one-semester study in one course with a limited number of students, there is a need for a longitudinal study with a larger diversified sample size at the development of this media in other courses.

\section{References}

[1] Abdullah, S. S. \& Yaacob, A. (2013); WHEN COMPELLED TO FB AROUND ACADEMIC TEXTS : POSTGRADUATE STUDENTS REFLECTED ON THEIR ONLINE EXPERIENCE, 10, 1-27.

[2] Asgari Arani, Jafar,(2012), TEACHING ENGLISH MEDICAL WRITING IN A BLENDED SETTING, International Journal of Emerging Technology, Volume 7, Issue 4, December.

[3] Asgari Arani,Jafar, (2016), MOBILE EDUCATIONAL SMSS AS SUPPLEMENTARY MEANS TO TEACH SENTENCE PARAPHRASING IN EMP COURSE, International Journal of Mobile Technology, Volume 10, Issue 1.

[4] Attewell, J., Savill- Smith, C., \& Douch, R. (2009). The Impact of mobile learning: Examining what it means for teaching and learning Retrieved from http://www.caryloliver.com/Library/ImpactOfMobileLearning.

[5] Bere, A. (2013). Using mobile instant messaging to leverage learner participation and transform pedagogy at a South African University of Technology. British Journal of Educational Technology, 44(4), 544-561. https://doi.org/10.1111/bjet.12057

[6] Bouhnik, D., \& Deshen, M. (2014). WhatsApp goes to school: Mobile instant messaging between teachers and students. Journal of Information Technology Education: Research, 13,217-231. Retrieved from http://www.jite.org/documents/Vol13/JITEv13ResearchP217231Bouhnik0601.pdf

[7] Brown, J. D. and Rodgers, T. S. (2002). Doing second language research. Oxford: Oxford University Press. 
[8] Cavus N. and Ibrahim D. (2009). "M-learning: An experiment in using SMS to support learning new English language words", British Journal of Educational Technology, Vol. 40, pp. 78-91. https://doi.org/10.1111/j.1467-8535.2007.00801.x

[9] Chipunza, P. R. C. (2013). Using mobile devices to leverage student access to collaboratively-generated re-sources: A case of WhatsApp instant messaging at a South African University. International Conference on Advanced Information and Communication Technology for Education (ICAICTE 2013).

[10] Church, K., \& de Oliveira, R. (2013). What's up with whatsapp? Comparing mobile instant messaging be-haviors with traditional SMS. Proceedings of the 15th International Conference on Human-computer Interaction with Mobile Devices and Services (pp. 352-361). ACM.

[11] Cifuentes, O. E., \& Lents, N. H. (2011). Increasing student-teacher interactions at an urban commuter campus through instant messaging and online office hours. Electronic Journal of Science Education, 14(1).

[12] Doering, A., Lewis, C., Veletsianos, G., \& Nichols-Besel, K. (2008). Preservice teachers' perceptions of instant messaging in two educational contexts. Journal of Computing in Teacher Education, 25(1), 5-12.

[13] Fischer, Y. (2013). "The Facebook is dead - long live WhatsApp". De Marker. Retrieved from http://www.themarker.com/technation/1.2126492.

[14] Gu, X., Gu, F. and Laffey, J.M. (2011), Designing a mobile system for lifelong learning on the move. Journal of Computer Assisted Learning, 27: 204-215 https://doi.org/10.1111/j.1365-2729.2010.00391.x

[15] Gutiérrez ,Mar - Colon, María - Escofet Isabel Gibert, Plana, M (2013),Improving learners' reading skills through instant short messages: A sample study using WhatsApp, Global perspectives on Computer- Assisted Language Learning, Glasgow, 10-13 July 2013, Available at: http://arts.ulster.ac.uk/worldcall2013/userfiles/file/shortpapers.pdf

[16] Hayati A. M. (2009). "M-learning”, English Teaching Professional, Vol. 64, pp. 56-58.

[17] Hemmi, Akiko, Bayne, Sian, Land, Ray (2009), The appropriation and repurposing of social technologies in higher education, Journal of Computer Assisted Learning. 25, 1, p. 193012 p. Retrieved from: http://www.research.ed.ac.uk/portal/en/searchall.html?searchall= The+appropriation + and + repurposing + of + social + technologies + in + higher + education

[18] Howard A. (2012). "Connecting with communities: How local government is using social media to engage with citizens", Australian Centre of Excellence for Local Government, University of Technology, Sydney, pp. 69-70.

[19] Hutchinson ,Tom and Waters, Alan, (1987 ), English for Specific Purposes: A LearningCentred Approach, First published 1987 ,22nd printing 2006 ,Printed in the United Kingdom at the Cambridge University Press. https://doi.org/10.1017/CBO9780511733031

[20] Iwata, J., Clayton, J. (2008). Using a perceptual measure to evaluate students' acceptance of digitally created English learning content. WorldCALL 2008 Proceedings, d-091-g-051, d_119

[21] Iwata, J., Tamaki, Y., Clayton, J. (2012). How can we measure CALL content? - Development of a Perceptual Measure to Evaluate CALL content. Medium Matters; 2012 CALL CONFERENCE Proceedings, 337-341.

[22] Jovanovic, Jelena - Chiong, Raymond and Weise, Thomas (2012) Social Networking, Teaching, and Learning, Interdisciplinary Journal of Information, Knowledge, and Management, Volume 7.

[23] Kempen G. and Harbusch K. (2002). "Performance grammar: A declarative definition", in: M. Theune, A. Nijholt \& H. Hondrop(Eds.), Computational Linguistics in the Netherlands, Amsterdam: Rodopi , pp. 148-162. 
[24] Kietzman J. (2011). "Social media? Get Serious? Understanding the functional building blocks of social media", Business Horizons, Vol. 54, pp. 241-251. https://doi.org/10.1016/ j.bushor.2011.01.005

[25] Kukulska-Hulme,(2007), Mobile Usability in Educational Contexts: What have we learnt? The International Review of Research in Open and Distributed Learning,vol. 8, No 2. Available at: http://www.irrodl.org/index.php/irrodl/article/viewArticle/356.

[26] Kukulska-Hulme,(2008), The Mobile usability in educational contexts, TD Tecnologie Didattiche Journal, vol. 16, No 2

[27] Kvale, S. and Birnkmann, S. (2009). Interviews: Learning the craft of qualitative research interviewing (2nd Ed.). London: Sage Publication.

[28] Lave J. and Wenger E. (1991). Situated Learning Computed, Cambridge: Cambridge University Press. https://doi.org/10.1017/CBO9780511815355

[29] Levy M. and Kennedy C. (2005). "Learning Italian via mobile SMS", in: A. KukulskaHulme \& J. Traxler (Eds.), Mobile Learning: A Handbook for Educators and Trainers, London: Taylor and Francis, pp.76-83.

[30] Li C. (2009). "SMS-based vocabulary learning for ESL students", unpublished dissertation, Auckland, NZ: Auckland University of Technology, School of Computing and Mathematical Sciences.

[31] Lu M. (2008). Effectiveness of vocabulary learning via mobile phone. Journal of Computer Assisted Learning, 24, 515-525. https://doi.org/10.1111/j.1365-2729.2008.00289.x

[32] Lung-Hsiang Wong, Wenli Chen, Ching-Sing Chai, Chee-Kuen Chin, Ping Gao,(2011), A blended collaborative writing approach for Chinese L2 primary school students, Australasian Journal of Educational Technology, 27(7). https://doi.org/10.14742/ajet.913

[33] Motallebzadeh and Ganjali, (2011), SMS: Tool for L2 Vocabulary Retention and Reading Comprehension Ability, Journal of Language Teaching and Research, Vol. 2, No. 5, pp. 1111-1115,

[34] Naismith, L., Lonsdale, P., Vavoula, G., \& Sharples, M. (2004). NESTA Future lab Report 11: Literature Review in Mobile Technologies and Learning. Bristol, UK: NESTA

[35] Nguyễn ThịTốHoa\& Phạm ThịTuyết Mai,(2016), Difficulties in Teaching English for Specific Purposes: Empirical Study at Universities, Higher Education Studies; Vol. 6, No. 2;, Published by Canadian Center of Science and Education.

[36] Prensky, M. (2001) Digital Natives, Digital Immigrants. On the Horizon, Vol. 9 No. 5, October (pp 1-6). https://doi.org/10.1108/10748120110424816

[37] Punch, Keit.F. (2014). Introduction to social research: Quantitative and Qualitative Approach, University of Western Australia. Third Edition, London: Sage Publication.

[38] Riyanto, A., 2013. English Language Learning Using 'WhatsApp' Application http://akhmadriyantbloog.wordpress.com/2013/07/21/english-language-learning-usingwhatsapp-application/

[39] Salem, A. A. M.(2013). The impact of technology (BBM and WhatsApp applications) on English linguis-tics in Kuwait. International Journal of Applied Linguistics \& English Literature, 2(4), 64-69.

[40] Smit, I. (2012). WhatsApp with BlackBerry; Can Messengers (BBM) be MXit?. In Proceedings of the 14th Annual Conference on World Wide Web Applications. Cape Peninsula University of Technology, Cape Town, South Africa.

[41] Sweeny, S. M. (2010). Writing for the instant messaging and text messaging generation: Using new literacies to support writing instruction. Journal of Adolescent \& Adult Literacy, 54(2), 121-130. https://doi.org/10.1598/JAAL.54.2.4

[42] Thornton P. and Houser C. (2001). "Learning on the move: Vocabulary study via email and mobile phone SMS", in: Proceedings of ED-MEDIA, pp. 1846-1847. 
Paper-An Innovative Media Platform-Supported Blended Methodology in English for Dental Purposes...

[43] Thornton, P. \& Houser, C. (2005); Using mobile phones in English education in Japan, Journal of Computer Assisted Learning, 21, 217-228. https://doi.org/10.1111/j.13652729.2005.00129.x

[44] Wagner, Laura. (2010) "Inferring meaning from syntactic structures in acquisition: The case of transitivity and telicity." Language and cognitive processes 25.10: 1354-1379. https://doi.org/10.1080/01690960903488375

[45] Williams, A., Birch, E., \& Hancock, P. (2012). The impact of online lecture recordings on student performance. Australasian Journal of Educational Technology, 28 (2), 199-213. https://doi.org/10.14742/ajet.869

[46] Yeboah, Johnson \& Ewur, George Dominic ,(2014), The Impact of Whatsapp Messenger Usage on Students Performance in Tertiary Institutions in Ghana, Journal of Education and Practice,

[47] Zepke, N., and Leach, L. (2010) Improving student engagement: Ten proposals for action. Active Learning in Higher Education. 11. (pp 167-177). https://doi.org/10.1177/ $\underline{1469787410379680}$

\section{Author}

Jafar Asgari Arani is with Kashan University of Medical Sciences, English department as a full time faculty member. He has published 22 papers in international journals and 9 textbooks. He also has presented 19 lectures at international scientific conferences.

Article submitted 25 November 2016. Published as resubmitted by the author 27 December 2016. 